\title{
PERAMALAN KECEPATAN ANGIN KOTA MANOKWARI MENGGUNAKAN JARINGAN SARAF TIRUAN UNTUK PERANCANGAN BALING-BALING KINCIR ANGIN
}

\author{
Tobias Tobi Tukan \\ ${ }^{1}$ Jurusan Fisika, FMIPA, Universitas Papua, Manokwari, 98314, Indonesia \\ *Email: t.tukan@unipa.ac.id
}

\begin{abstract}
ABSTRAK
Telah dilakukan penelitian peramalan kecepatan angin kota Manokwari dan perancangan baling-baling kincir angin. Terdapat empat parameter input, yaitu: temperatur udara, kelembaban udara, curah hujan dan kecepatan angin. Arsitektur jaringan bisa digunakan adalah satu lapisan, dengan jumlah neuron 80. Hasil ramalan kecepatan angin berkisar 4,1 - 9,62 m/s. Pada rancangan baling-baling kincir angin yang digunakan airfoil NACA 4412, 4415 dan 4418. Jenis baling-baling taperless dengan lebar ujung sampai pangkal baling-baling dibuat konstan $(C r=0,18 \mathrm{~m})$. Hasil penelitian menunjukkan bahwa airfoil NACA 4412 lebih baik dari kedua airfoil NACA 4415 dan 4418. Daya keluaran dapat dicapai sekitar 982,01 W pada $200 \mathrm{rpm}$ untuk airfoil NACA 4412.
\end{abstract}

Kata kunci: Angin, peramalan, jaringan saraf tiruan, kincir angin, baling-baling, NACA 4412, NACA 4415, NACA 4418.

\begin{abstract}
Design of wind turbine blade based on forecasting of wind speed in Manokwari city has been successfully conducted. In the recent work, wind speed forecasting using a neural network was designed with three parameters namely temperature, relative humidity and rainfall as input layer and one hidden layer which consists of 80 neurons whilst wind speed will be used as output layer. The result showed that an estimate of the wind speed in Manokwari based on the forecasting was $4.1-9.62 \mathrm{~m} / \mathrm{s}$. Meanwhile the design of the wind turbine blades were designed using airfoil NACA 4412, 4415 and 4418. Taperless blades were prepared with the same size from propeller base to propeller tip $(C r=0.18 \mathrm{~m})$. The results showed that Airfoil NACA 4412 is better than both Airfoil NACA 4415 and 4418. The output power can be achieved around 982.01 W at $200 \mathrm{rpm}$ for Airfoil NACA 4412.
\end{abstract}

Keywords: wind, forecasting, neural network, wind turbine, blade, NACA 4412, NACA 4415, NACA 4418. 


\section{PENDAHULUAN}

Angin merupakan udara yang bergerak karena adanya perbedaan tekanan dan diakibatkan oleh rotasi bumi. Udara yang bergerak akan semakin kencang bila perbedaan tekanan daerah tersebut semakin besar. Variabel yang mempengaruh pergerakan kecepatan angin diantaranya temperatur, kelembaban dan curah hujan. Untuk mengetahui besarnya kecepatan angin suatu daerah, maka diperlukan kajian dalam bentuk peramalan tentang kecepatan angin. Salah satu metode yang digunakan dalam melakukan peramalan adalah Jaringan Saraf Tiruan. Jaringan Saraf Tiruan adalah paradigma pemrosesan suatu informasi yang terinspirasi oleh sistim sel saraf biologi, sama seperti otak yang memproses suatu informasi (Fausett dan Laurene, 1994).

Purnama.A, 2011, dalam peramalan kecepatan angin menggunakan JST di Bali diperoleh nilai error 0,0017, hasil peramalan kecepatan angin 0,412 - 4,64 $\mathrm{m} / \mathrm{s}$. Daya total minimum yang dihasilkan pada rentang kecepatan angin tersebut adalah $14 \mathrm{~W}$, daya maksimumnya 19.649 W dan daya rata-ratanya adalah 4324,086 W. Ali Musyafa,dkk, 2009 dalam penelitian peramalan kecepatan angin menggunakan metode JST di ladang angin Sampang, Mojokerto dan Nganjuk.
Diketahui lokasi Nganjuk yang memiliki tiga input dan satu output, hasil uji nilai RSME 0,017 dan nilai VAF 99,1 dengan epochs 286. Hasil desain turbin angin dengan simulasi mampu menghasilkan konstanta daya $(C P) 0,59$, daya angin 479 $\mathrm{W} / \mathrm{s}$ pada kecepatan angin $7,5 \mathrm{~m} / \mathrm{s}$ dan daya angin $373 \mathrm{~W} / \mathrm{s}$ untuk kecepatan angin $4 \mathrm{~m} / \mathrm{s}$. Hasil pengujian protipe turbin angin mampu menghasilkan konstanta daya $(C P) \quad 0,545$, daya angin $426 \mathrm{~W} / \mathrm{s}$ pada kecepatan angin $7,5 \mathrm{~m} / \mathrm{s}$, serta daya angin $345 \mathrm{~W} / \mathrm{s}$ untuk kecepatan angin $4 \mathrm{~m} / \mathrm{s}$.

Sumber energi listrik selama ini digunakan adalah energi fosil (minyak bumi dan batubara), namun sangat terbatas dan menipis (Y. Daryanto, 2007). Untuk mengatasi permasalahan tersebut, diperkenalkan pengganti energi fosil yaitu energi angin, dimana memanfaatkan angin sebagai sumber pembangkit listrik. Alat pembangkit listrik tenaga angin selama ini dikenal adalah kincir angin, pada kincir angin untuk menghasilkan daya maksimum salah satu faktor yang mempengaruhi adalah desain balingbaling kincir angin. Dan dalam melakukan desain baling-baling kincir angin parameter yang sangat berpengaruh adalah kecepatan angin (Pigott. H, 2000).

Umumnya masyarakat Manokwari memanfaatkan energi dari energi fosil, sehingga informasi mengenai energi 
alternatif sebagai pengganti energi fosil sangat dibutuhkan untuk pengembangan ke depan. Maka setelah mengetahui ramalan kecepatan angin dari arsitektur jaringan saraf tiruan, selanjutnya dilakukan desain baling-baling kincir angin yang cocok dipergunakan di Manokwari.

\section{METODE PENELITIAN}

Pada penelitian ini jenis jaringan saraf yang digunakan adalah Multilayer Perceptron propagasi balik algoritma Levenberg Marquardt, pengolahannya menggunakan software Matlab2010a. Data-data input dan output digunakan merupakan data bulanan periode 2004 2014 yang diperoleh dari stasiun meteorologi dan geofisika Manokwari. Data-data input yang diantaranya curah hujan, suhu dan kelembaban, dan outputnya adalah kecepatan angin. Data 2004 - 2011 digunakan sebagai pelatihan dan data 2012 -2014 akan digunakan untuk menguji.

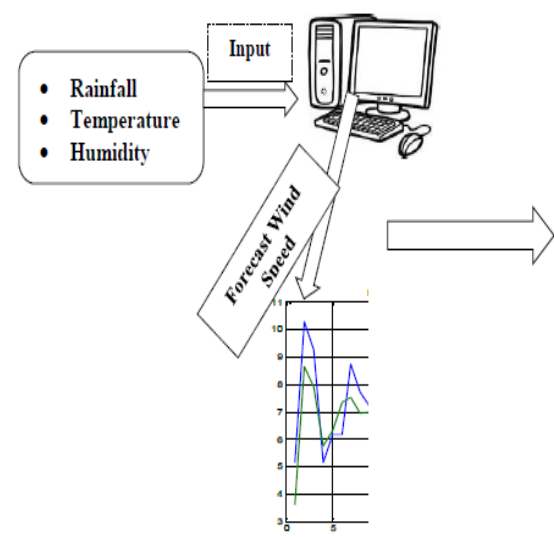

(a

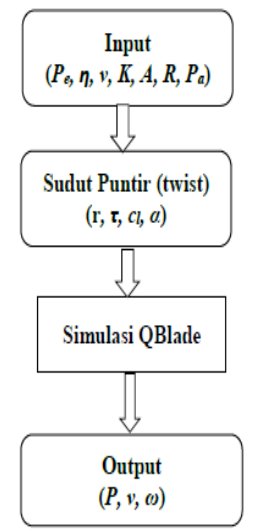

(b
Gambar 1 (a) Teknik peramalan kecepatan angin. (b) Teknik desain baling-baling kincir angin

Untuk desain baling-baling menggunakan software Excel dan QBlade, dengan baling-baling kincir angin airfoil seri NACA 4412, 4415 dan 4418. Proses desain baling-baling kincir angin pada penelitian ini terdiri dari tiga tahapan, yaitu: penentuan geometri dasar (input) baling-baling kincir angin, perhitungan sudut puntir baling-baling, simulasi baling-baling (Pigott. H, 2000). Parameter-parameter geometri dasar baling-baling kincir angin adalah daya listrik $(P e)=1500 \quad \mathrm{~W}$, efisiensi $(\eta)$ transmisi, generator, controller masingmasing 90\%, efisiensi baling-baling sebesar $30-40 \%$, kecepatan angin yang diperlukan $\left(v_{\max }\right) 12 \mathrm{~m} / \mathrm{s}$, panjang balingbaling 1,5 m, Tip Speed Ratio (TSR = 7), lebar baling-baling $(C r)=0,18 \mathrm{~m}$, jumlah baling-baling $(B)=3$. koefisien sistem $(K)$, luas sapuan $(A)$, jari-jari $(R)$, dan daya angin $(\mathrm{Pa})$. Persamaan-persamaan yang digunakan adalah (Hansen. O.L.Martin, 2008).

$$
\begin{gathered}
K=\eta_{\text {blade }} \times \eta_{\text {transmisi }} \times \eta_{\text {generator }} \times \\
\eta_{\text {kontrol }} \\
A=2 \frac{P_{\text {wind }}}{\rho v^{3}} \\
R=\sqrt{\frac{A}{\pi}}
\end{gathered}
$$




$$
W_{a}=\frac{W_{e}}{K}
$$

Parameter-parameter masukan yang digunakan dalam perhitungan sudut puntir baling-baling adalah: elemen balingbaling, jari-jari parsial ( $r$, TSR parsial, koefisien gaya angkat $c l$ (lift), sudut serang $\alpha$ (angle of attack), sudut aliran fluida $\phi$ (flow angle), sudut puntir $\beta$ (twist). Elemen baling-baling dibagi dalam 10 elemen, masukan nilai innermost station atau jarak dari pusat hub ke bagian baling-baling yang tidak menempel ke generator digunakan adalah 0,25 m. Persamaan-persamaan yang digunakan adalah (Hansen. O.L.Martin, 2008):

$r=0,25+\left[\left(\frac{R-0,25}{n}\right)\right] \times$ elemen

$\beta=\phi-\alpha, \quad \phi=\frac{2}{3} \tan ^{-1} \frac{1}{\lambda_{r}}$

$\lambda_{r}=\frac{r}{R} \times \lambda$

$C_{l}=\frac{16 \pi R(R / r)}{9 \lambda^{2} B C_{r}}$

Untuk simulasi baling-baling kincir angin, tahapan yang harus dilewati adalah Ekstrapolasi polar, simulasi rotor, simulasi parameter Blade Element Momentum (BEM). Parameter masukan dalam melakukan simulasi BEM adalah range kecepatan angin $1-12 \mathrm{~m} / \mathrm{s}$, range kecepatan putaran 100 - 500 rpm dan pitch range.Output yang diharapkan adalah hubungan antara daya $(P)$ terhadap kecepatan angin $(v)$ pada setiap kecepatan sudut $(\omega)$.

\section{HASIL DAN PEMBAHASAN}

Hasil ramalan kecepatan angin terbaik, ketika diuji menggunakan arsitektur jaringan yang dibangun dengan jumlah maksimum epochs $=1000$, gradient minimum $=1 \times 10^{-10}$, learning rate $=0,001$, maximum fail $=30$, show step $=25$, satu lapisan tersembunyi dan 80 neuron, fungsi aktivasi yang digunakan adalah sigmoid. Hasil simulasi

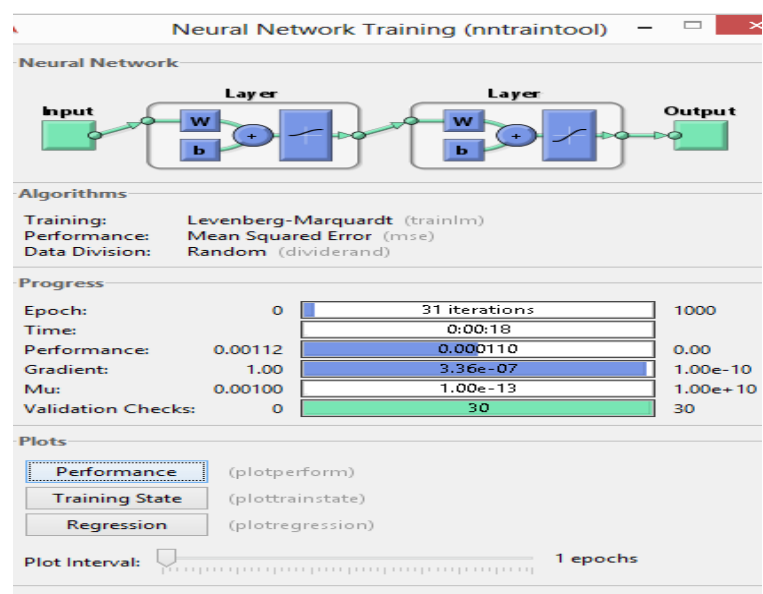

ditunjukkan di bawah ini.

Gambar 2. Arsitektur jaringan dan hasil training

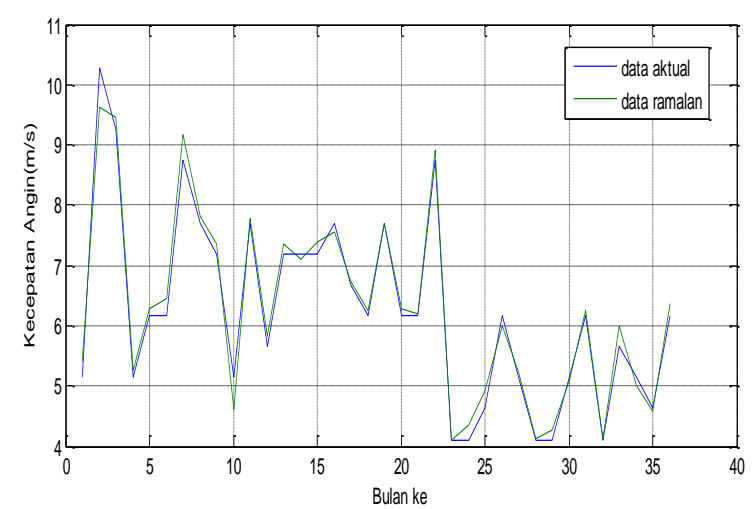


Gambar 3. Grafik hasil peramalan kecepatan angin

Hasil training nilai Mean Square Error $(\mathrm{MSE})=$ 0,00011 pada epochs 31, koefisien determinasi $R$ adalah 0,98 . Berdasarkan gambar 2 hasil peramalan kecepatan angin diperoleh mendekati data aktual, dengan kecepatan angin hasil ramalan untuk tahun 2012 - 2014 adalah 4,1 - 9,62 m/s. Dengan demikian dapat dikatakan bahwa arsitektur jaringan saraf tiruan ini dapat digunakan untuk melakukan ramalan kecepatan angin untuk dua tahun mendatang.

Sedangkan hasil desain baling-baling kincir angin untuk ketiga jenis airfoil NACA ditampilkan pada grafik-grafik dibawah ini:

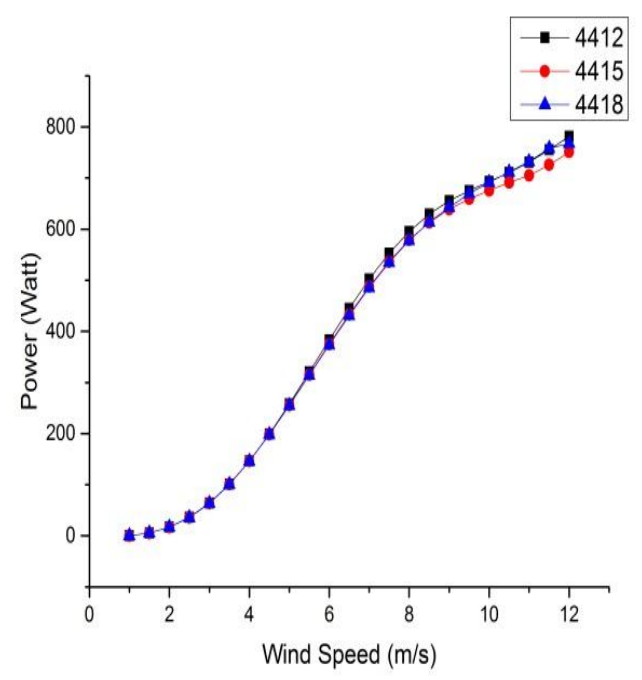

Gambar 4. Grafik Power Vs Wind speed pada $\omega=100 \mathrm{rpm}$

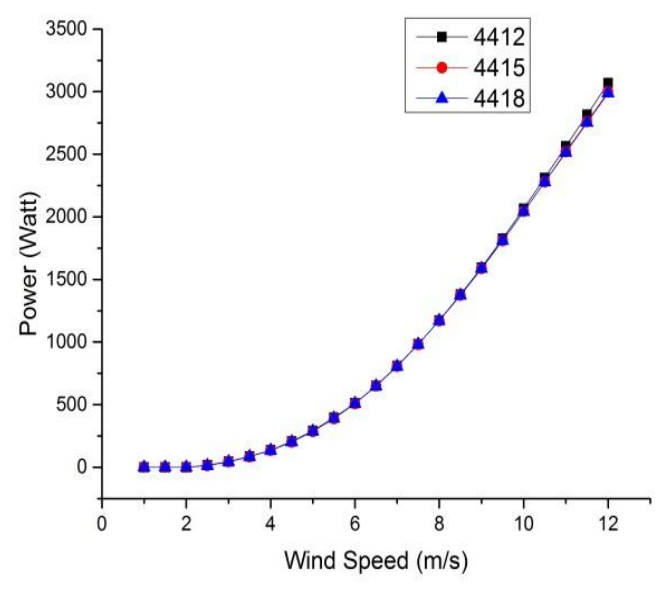

Gambar 5. Grafik Power Vs Wind speed pada $\omega=200 \mathrm{rpm}$

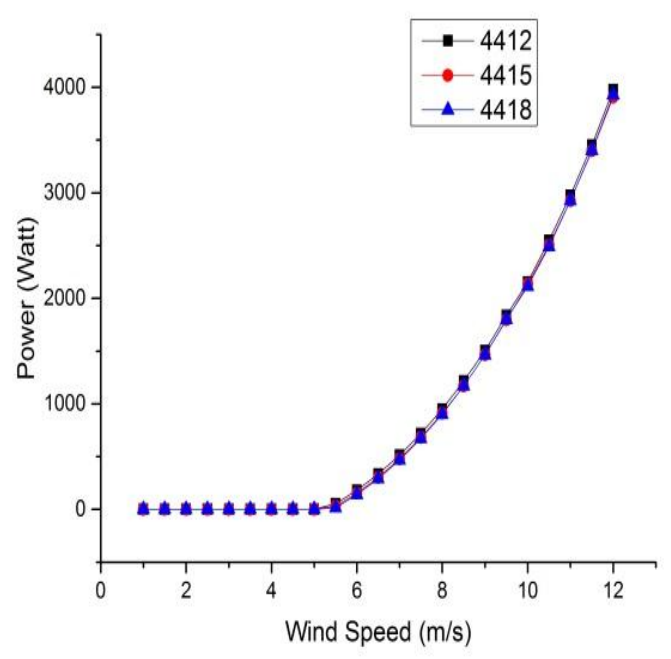

Gambar 6. Grafik Power Vs Wind speed pada $\omega=300 \mathrm{rpm}$

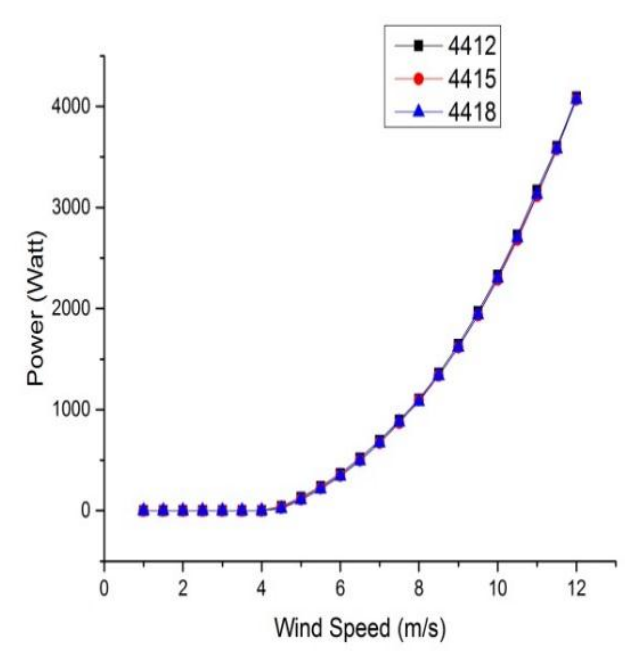

Gambar 7. Grafik Power Vs Wind speed pada $\omega=400 \mathrm{rpm}$ 


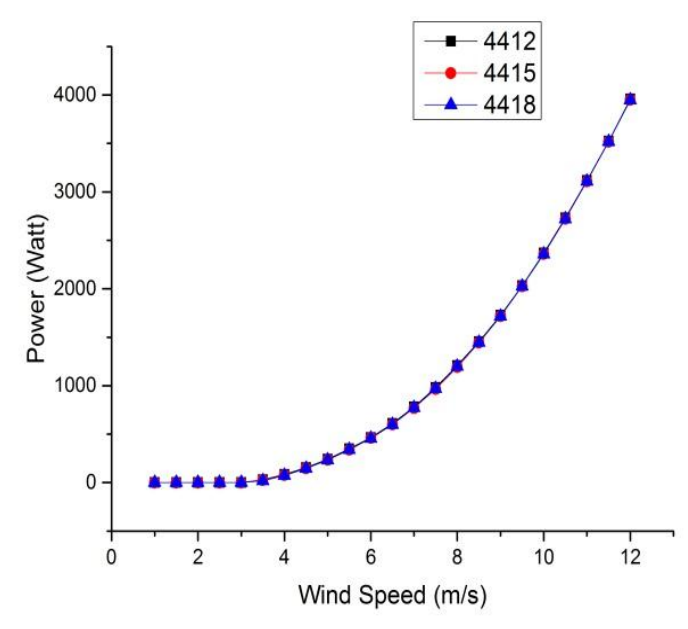

Gambar 8. Grafik Power Vs Wind speed pada $\omega=500 \mathrm{rpm}$

Hasil desain baling-baling kincir angin pada gambar 4 sampai 8 diatas tampak bahwa airfoil NACA 4412 mempunyai daya minumam dan maksimum lebih besar daripada kedua jenis NACA 4415 dan NACA 4418. Daya minimum pada airfoil NACA 4412 yang diperoleh adalah $5,75 \mathrm{~W}$ pada kecepatan angin $1,5 \mathrm{~m} / \mathrm{s}$ dan kecepatan sudut 100 rpm, sedangkan daya maksimumnya adalah 4094,34 W pada kecepatan angin $12 \mathrm{~m} / \mathrm{s}$ dan kecepatan sudut 400 rpm. Pada kecepatan angin 4,1 - 9,62 m/s desain baling-baling kincir angin dapat menghasilkan daya $(P)$, sehingga desain airfoil NACA 4412, 4415 dan 4418 dapat dipergunakan didaerah Manokwari.

\section{KESIMPULAN}

Arsitektur jaringan berhasil dibangun dengan satu lapisan tersembunyi dan 80 neuron. Hasil training nilai Mean Square Error (MSE) 0,0011 pada epochs ke 31 dan koefisien determinasi $R=0,98$. Kisaran kecepatan angin hasil ramalan adalah 4,1 - 9,62 m/s. Hasil ramalan kecepatan angin diperoleh adanya kecenderungan baik antara data aktual dan data ramalan. Pada kecepatan angin tersebut hasil desain baling-baling kincir angin airfoil NACA 4412, 4415 dan 4418 dapat menghasilkan daya, sehingga ketiga jenis airfoil NACA ini dapat dipergunakan didaerah Manokwari.

\section{DAFTAR PUSTAKA}

Fausett, Laurene. (1994), Fundamental of Neural Network, Prentice Hall, New Jersey.

Hadi Suyono. (2010), Kajian Potensi Energi Angin di Wilayah Indonesia Timur, Puslibang BMKG, Jakarta.

Hansen. O.L.Martin. (2008), Aerodinamics of Wind Turbines, $2^{\text {nd }}$ ed, Published by Earthscan in the UK and USA. 
Johnson, Gary. L. (2006), Wind Energy

System, Manhattan-KS.

M. Ali, Agus Dharma I.Made Yulistia Negara, Imam Robandi. (Juli 2009), Kajian Potensi Tenaga Angin di Tiga Lokasi, Sampang, Mojokerto dan Nganjuk di Jawa Timur, Proceeding National Conference, Fakultas Teknologi Industri - ITS Surabaya.

Pigott. H. (2000), Windpower Workshop, Peninsula: British Wind Energy Associatio.

Purnama Adek. (2011), Peramalan Kecepatan Angin Jangka Pendek Untuk Pembangkit Listrik Tenaga Bayu Menggunakan Jaringan Saraf Tiruan Propagasi Balik, Teknik Elektro Universitas Indonesia, Jakarta.

Y. Daryanto. (2007), Kajian Potensi Angin untuk Pembangkit Listrik Tenaga Bayu, Balai PPTAGGUPT-LAGG, Indonesia, Yogyakarta. 